\title{
Escrever a tradição, modernizar a nação: literatura e identidade nacional durante 0 Estado Novo de Vargas (1937-1945) 1
}

\author{
Writing Tradition, Modernizing the Nation: Literature and \\ National Identity during Vargas' Estado Novo (1937-1945)
}

Gabriela de Lima Grecco*

Resumo: Este artigo procura, através de fontes primárias oriundas, principalmente, do CPDOC (FGV) e do Arquivo Público de São Paulo, analisar as políticas de promoção do livro durante o Estado Novo (1937-1945), período em que o Estado investiu na criação da categoria de "livros da Nação", fundando, para tanto, o Instituto Nacional do Livro. Serão analisadas as três seções do Instituto (a Seção da Enciclopédia e do Dicionário, de Bibliotecas e de Publicações), no intuito de se compreender se os instrumentos de promoção da leitura desenvolvidos no período foram coerentes com os seus objetivos e se guardaram relação estrita com a ideologia do regime. Busca-se também entender seus êxitos, fracassos e suas inconsistências. Pretende-se, com isso, contribuir para a compreensão da política de fomento do livro e da leitura, identificando, especialmente, o papel dos intelectuais nas políticas públicas.

Palavras-chave: Estado Novo; Instituto Nacional do Livro; Literatura.
Abstract: Through primary sources, coming mainly from CPDOC (FGV) and the Public Archive of São Paulo, this article seeks to analyze the policies of book promotion during the Estado Novo ("New State", 1937-1945), a period in which the State invested in the creation of the category of "books of the Nation", founding the National Book Institute. The three sections of the Institute (the Encyclopedia and Dictionary Section, the Libraries Section, and the Publications Section) will be analyzed in order to understand if the instruments developed during the period to promote reading were coherent with its objectives and if they were strictly related to the ideology of the regime. We also seek to understand its successes, failures and inconsistencies. By this means, the article intends to comprehend the policy of promoting books and reading, identifying, especially, the role of intellectuals in public policies.

Keywords: New State; National Book Institute; Literature.

\footnotetext{
* Universidad Autónoma de Madrid (UAM), Madrid, Espanha. gabrielalimagrecco@gmail.com $<$ https://orcid.org/0000-0002-7137-5251>
} 
As políticas de promoção da leitura tornaram-se uma questão central para os Estados no início do século XX. Em muitos países da Europa e da América Latina, aumentou-se a valorização do livro ao torná-lo ferramenta dos anseios populares. A Itália foi um exemplo importante dessas mudanças. Neste país, entre os anos de 1903 e 1922, foram levadas a cabo várias iniciativas para a promoção da leitura, vistas como uma forma de elevação espiritual, social, civil e cultural das classes populares, a partir da liderança de importantes intelectuais socialistas, como Ettore Fabietti. Entre estas iniciativas estavam o Consórcio de Bibliotecas Populares e o Istituto Italiano per il Libro del Popolo. No entanto, com a ascensão do governo fascista ao poder (1922), e por meio de um processo de fascistização das instituições, criou-se o Istituto $\mathrm{Na}$ zionale Fascista di Cultura sob o comando de Benito Mussolini (Turati, 1905). Este novo modelo de promoção literária, cujo fomento deveria realizar-se por um Estado autoritário, serviu de referência a muitos países, em particular ao governo do Estado Novo de Getúlio Vargas.

Durante os anos trinta, diversos governantes de diferentes países, influenciados por estas novas políticas estatais, criaram organismos com o objetivo de centralizar as políticas de promoção do livro, tais como o Instituto Nacional do Livro no Brasil, sob o governo de Getúlio Vargas; na Espanha, o Instituto del Libro Español, que, em 1939, passou a chamar-se Instituto Nacional del Libro Español, sob o comando do general Francisco Franco ${ }^{2}$; em Cuba, o Instituto del Libro cubano; e no México, o Instituto del Libro mexicano. Desta forma, a criação do Instituto Nacional do Livro (INL) no Brasil pode ser entendida a partir de um projeto mais global de centralização cultural, que passava pela criação de organismos oficiais por parte dos Estados em relação à leitura e ao livro.

As elites intelectuais podem ser consideradas, nesta etapa histórica, como agentes legitimadores de uma nova ordem sociopolítica e suas atividades estiveram vinculadas à missão de consolidação de uma política modernizadora do país ${ }^{3}$, bem como de elaboração de uma política cultural nacionalizadora. Desempenharam, portanto, como observou Musiedlak (2006), um duplo papel de militantes e burocratas. Houve, portanto, no caso brasileiro, uma adesão ao regime, de serviço à nação, mas, por outro lado, se os intelectuais aderiram a uma "ideologia de Estado", o Estado aderiu a uma "ideologia da cultura". Neste artigo, portanto, pretende-se analisar a importância da criação do INL dentro da lógica nacionalizadora e "modernizadora" do Estado Novo de Getúlio Vargas (1937-1945), bem como examinar a identificação das elites intelectuais com o Estado como impulsor da nacionalidade brasileira. 


\section{O Instituto Nacional do Livro no Brasil}

Assim como no caso de outros países latino-americanos, de meados do século XIX até a Primeira Guerra Mundial o Brasil dependia da importação de papel, de máquinas gráficas e da mão-de-obra especializada para a edição de livros. Neste período, o mercado editorial brasileiro era escasso, existiam poucos autores de literatura ${ }^{4}$, vendiam-se poucos livros, o público leitor era reduzido $^{5}$ e as oficinas tipográficas eram antiquadas. De acordo com Hallewell (2012), o mercado de livros era muito limitado e o comércio livreiro estava circunscrito, basicamente, aos livros didáticos e sobre a legislação brasileira, bem como à venda de obras francesas.

No entanto, este panorama mudou drasticamente nas décadas posteriores - podendo-se falar de um boom editorial neste período (Pagano, 2001) -, particularmente em razão de mudanças tanto internas como externas ao país. Por um lado, desde o ponto de vista externo, a indústria editorial brasileira conseguiu desenvolver-se e tornar-se independente da europeia, já que esta etapa se caracterizou por dificuldades do comércio internacional e, paralelamente a este fenômeno, os livros europeus tornaram-se caros (Miceli, 2001). Por outro lado, internamente, algumas editoras, como a Editora José Olympio, a Companhia Editora Nacional ou a Monteiro Lobato \& Cia inovaram na distribuição dos livros, nos aspectos gráficos e, inclusive, apoiaram um tipo de literatura mais conectado aos interesses de um público leitor mais amplo e diverso ${ }^{6}$ com traços orais da linguagem tipicamente nacional, coloquialismos e temas de interesse social (Passiani, 2002). Como destacou o historiador Roger Chartier (2005), as formas pelas quais que se oferece a leitura participam também da construção de sua significação. Assim, estas novas práticas transformaram o livro numa mercadoria atraente e rentável (Dutra, 2004, p. 4).

Paralelamente a estas mudanças, também se pode destacar o incremento do público leitor. Nas primeiras décadas do século XX, a cidade de São Paulo dobrou sua população, passando de quinhentos mil habitantes a um milhão. Esse crescimento, somado ao desenvolvimento do transporte ferroviário, ao aumento de um mercado consumidor urbano e à redução das taxas de analfabetismo - 75\% da população com mais de seis anos em São Paulo estava alfabetizada -, fez com que a indústria editorial brasileira, tanto a de São Paulo quanto a do Rio de Janeiro, tornassem-se as mais pujantes. O desenvolvimento do público leitor e a profissionalização dos escritores foram dois fenômenos complementares desse cenário positivo do reino das letras (Souza, 2003, pp. 46-48). No quadro abaixo, é possível se observar a evolução populacional e a 
diminuição do analfabetismo no Brasil. Ao longo das décadas de 1920, 1940 e 1950, a taxa de analfabetismo diminuiu, embora o número absoluto aumentasse em relação ao aumento da população. Entretanto, se observados os dados, chega-se à conclusão de que o Brasil contava, no final da década de trinta, com aproximadamente 19 milhões de potenciais leitores.

\begin{tabular}{|c|c|c|c|}
\hline \multicolumn{4}{|c|}{ Tabela 1 } \\
\hline \multirow{3}{*}{ Analfabetismo no Brasil (a partir dos cinco anos) $-1900 / 1950$} \\
\hline \multirow{2}{*}{ Ano } & População & Analfabetos & $\begin{array}{c}\text { Taxa de } \\
\text { analfabetismo }\end{array}$ \\
\cline { 2 - 4 } & Brasil & Brasil & Brasil \\
\hline 1920 & 30.635 .605 & 18.549 .085 & 71,2 \\
\hline 1940 & 41.165 .289 & 21.295 .490 & 61,1 \\
\hline 1950 & 51.941 .767 & 24.907 .696 & 57,1 \\
\hline
\end{tabular}

Fonte: Elaboração própria. Dados colhidos do IBGE/Recenseamento Geral do Brasil (Estadísticas Históricas do Brasil).

Com a instauração do regime de Getúlio Vargas, em 1937, iniciou-se, no Brasil, uma política pública e centralizadora para o livro, com a finalidade de se criarem mecanismos institucionais para se difundir a leitura nas diversas comunidades e regiões do país (Oliveira, 1994). Nesse contexto político-intelectual, os espaços de sociabilização e de difusão da leitura, como as bibliotecas, passaram a ser controlados pelo Estado. No Brasil, as mudanças no âmbito do livro foram sendo configuradas lentamente e surgiram novos livros, novos discursos e novos usos e práticas sociais de leitura ${ }^{7}$. O Governo do Estado Novo iniciou a difusão de valores ideológicos por meio de políticas públicas destinadas a fomentar a cultura nacional e, por esse motivo, o ministro Gustavo Capanema sugeriu a criação de um instituto que centralizasse a política do livro, para difundir e "proteger" o livro e a leitura.

O Instituto Nacional do Livro (INL) foi criado pelo Decreto-Lei n. 93, em 21 de dezembro de 1937, para ocupar o lugar do Instituto Cairu (Lei n. 378, art. 44, em 13 de janeiro de 1937). Criaram-se, então, três seções: a Seção da Enciclopédia e do Dicionário; a Seção de Publicações e a Seção de Bibliotecas. Essas três seções - o "tripé" do Instituto - tiveram como primeiros chefes, respectivamente, os intelectuais Américo Facó, Sergio Buarque de Holanda e Augusto Meyer. O presidente Getúlio Vargas nomeou Augusto Meyer como diretor e este acumulou dois cargos: de diretor do Instituto e de chefe 
da seção de Bibliotecas (Arquivo Getúlio Vargas c 24 dez. 1937). Assim, o INL contou com a colaboração dos intelectuais que formavam a chamada Constelação Capanema: Mário de Andrade, chefe da Seção do Dicionário e da Enciclopédia Brasileira; Sérgio Buarque de Holanda, chefe da Seção de Publicações; e, entre os assessores técnicos, encontravam-se Graciliano Ramos e Vinicius de Moraes - intelectuais que seriam os mediadores simbólicos entre o popular e o nacional.

O INL deveria ser o encarregado de estabelecer as diretrizes básicas para a formação dos brasileiros a partir da leitura. Para cumprir sua missão, como órgão dependente do Ministério da Educação e Saúde, o INL tinha como eixo central de atuação três incumbências: cuidar, de maneira geral, da divulgação dos livros brasileiros; orientar o conteúdo dos livros brasileiros conforme as diretrizes da Constituição de 1937; e nacionalizar as obras brasileiras por meio da linguagem (Arquivo Gustavo Capanema 7 set. 1934-1).

O Instituto buscou reconfigurar o panorama literário brasileiro, exercendo a função tanto de editor quanto de cliente das livrarias e editoras. Cabia ao Instituto publicar obras raras e valiosas que fossem de grande interesse à cultura nacional e fazê-lo a preços acessíveis. Da mesma forma, o órgão investiu na difusão de obras de qualidade literária e propôs reformas legais que melhorassem, difundissem e abaratassem a produção de livros. O INL ficou encarregado, também, da elaboração de uma enciclopédia, cujos parâmetros foram as publicações estrangeiras, a partir de modelos inspirados nas enciclopédias britânicas, alemãs e no modelo mais recente na época, a Enciclopédia Treccani, do governo fascista de Mussolini.

Outra atribuição do INL foi produzir uma bibliografia nacional atualizada, além de dar início à criação de bibliotecas públicas, bem como organizar e ajudar na gestão das mesmas em todo o território do país. Essa política procurou orientar o que deveria ser lido e o que deveria ser editado e divulgado nas bibliotecas (Leitão, 2011, p. 146). Além disso, o INL articulou um censo de bibliotecas, a partir do qual cerca de 1.325 bibliotecas foram registradas em 1941 (Bragança, 2009, p. 227). O objetivo era que se tivesse um maior controle das bibliotecas por meio de subvenções públicas e, por outro lado, que os intelectuais passassem a trabalhar como intérpretes da realidade nacional. Tratava-se, portanto, de se converter tanto bibliotecas e livros quanto intelectuais em instrumentos do Estado. 


\section{ENCICLOPÉdiA BRASILEIRA E DiCIONÁRIO DA \\ LÍNGUA NACIONAL: A FORMAÇÃO DO ESPÍRITO BRASILEIRO}

A partir da década de trinta, o Estado brasileiro recrutou vários intelectuais de diferentes procedências para que se somassem à administração pública, participando da construção de uma cultura oficial. Para a elaboração da Enciclopédia, o ministro Gustavo Capanema convocou Mário de Andrade e outros autores reconhecidos. Para a sua execução, em uma primeira etapa da elaboração do projeto, o Governo contratou Eugenio de Castro, Aurélio Porto e os funcionários auxiliares Fernando Augusto de Amorim Garcia, Maria Pacheco Chaves e Luiza Amoroso Teixeira de Castro. Alguns anos depois, quando o Instituto Cairu já respondia como Instituto Nacional do Livro, o escritor Mário de Andrade ocupou o cargo de consultor técnico (Arquivo Gustavo Capanema 7 set. 1934-1).

Em junho de 1936, o Instituto Cairu dava seus primeiros passos na sua sede estadual da Biblioteca Nacional (Rio de Janeiro), com o objetivo de começar a criar a Enciclopédia Brasileira. Aurélio Porto esboçou uma das primeiras propostas para a elaboração desta: em sua opinião, ela deveria estar estruturada a partir das literaturas mundiais mais relevantes. A enciclopédia deveria recolher feitos e nomes históricos das seguintes literaturas: inglesa, italiana, alemã, francesa, espanhola, portuguesa, brasileira, grega e latina. Quanto aos modelos concretos em que a obra deveria estar inspirada, o principal modelo foi a Enciclopédia italiana Treccani.

Como foi salientado no trabalho de Laurence Hallewell (2012, p. 313), as políticas de Vargas consideravam urgente edificar uma cultura nacional a partir da compilação do saber brasileiro em uma única obra. Para esse fim, o ditador se inspirou no modelo italiano, assim como no projeto enciclopédico que recentemente desenvolvera Salazar em Portugal. A Enciclopédia italiana foi a escolhida, por ter sido a primeira publicação organizada a partir do Estado, além de concebida por um regime com muitos pontos em comum com o brasileiro, uma vez que a Itália também era uma ditadura nacionalista. Inclusive, pretendia-se fechar um acordo entre os governos italiano e brasileiro para que a Enciclopédia Treccani fornecesse a maquinaria e a equipe técnica para a elaboração da Enciclopédia brasileira. Esta adotou mais algumas características da Enciclopédia italiana: a tipografia, alguns tipos de conteúdo e a forma de financiamento.

O Instituto Cairu esboçou uma possível organização para realizar esse difícil projeto, chegando num resultado muito mais modesto que o italiano: a 
comissão diretora da Enciclopédia estava constituída por um diretor, três pessoas de "notável conhecimento"; dois assistentes (um para o Dicionário e outro para a Enciclopédia); quarenta colaboradores fixos; colaboradores autônomos para as notas de consulta (os "verbetes"); um secretário, quatro datilógrafos e um arquivista; e, por fim, uma comissão gráfica artística. De acordo com o relatório da primeira equipe, o Instituto deveria estar concentrado, em princípio, nos estudos das condições coetâneas e da formação histórica do Brasil, dedicando-se à organização de um léxico brasileiro (Arquivo Gustavo Capanema 7 set. 1934-1). A proposta era, também, a confecção de um dicionário de geografia, história, etnografia, biografia e bibliografia do Brasil. Tudo isso configuraria a etapa preliminar à criação da Grande Enciclopédia Brasileira.

Como foi referido anteriormente, o INL foi criado poucas semanas depois da instauração do Estado Novo e teve na figura de Mário de Andrade seu principal ideólogo. O escritor tinha fundado a Sociedade de Etnografia e Folclore e ocupou cargos culturais na administração municipal, uma vez que, em 1935, foi nomeado chefe do Departamento de Cultura pelo prefeito de São Paulo, Fábio da Silva Prado. No Departamento de Cultura, Andrade teve a oportunidade de criar o Laboratório de Fonética, cujo principal objetivo era gravar as pronúncias cultas e populares das diversas regiões do Brasil. Quando ocupou a direção da Seção de Enciclopédia e Dicionário no INL, salientou que esse instituto daria aos brasileiros leituras necessárias "de suaves tendências espirituais". A língua deveria espiritualizar, fazer com que o povo amasse sua cultura, pois, enquanto ele não a amasse, ela "não se integraria ao espírito" (Conferência a espiritualidade da língua).

Portanto, enquanto o Dicionário de Língua Brasileira deveria incorporar o vocabulário específico da fala brasileira, a Enciclopédia deveria tratar da história, da literatura e da cultura do país. Livros como A influência africana no português do Brasil, de Renato Mendonça, fizeram parte deste projeto nacionalista de pesquisa étnica e linguística do governo: um empreendimento editorial que encontrou terreno fértil na política cultural construída pelo Estado. Além disso, tanto o Dicionário quanto, principalmente, a Enciclopédia brasileira inspiraram-se em projetos anteriores, como na Biblioteca Pedagógica - e a criação da sua $5^{\text {a }}$ coleção, Brasiliana ${ }^{8}$-, elaborada pela Companhia Editora Nacional, ou, também, na Coleção Documentos Brasileiros, editada pela Editora José Olympio. A palavra brasiliana denota toda coleção que reúne os "livros que devem ser lidos para conhecer o Brasil” (Sorá, 2010, p. 28). Esta coleção serviu de modelo para a criação de políticas culturais estadonovistas, o que demonstra os estreitos vínculos político-institucionais entre as editoras privadas e o governo federal. Como 
destacou Maria Rita Toledo (2001), as elites intelectuais depositaram nos livros a missão de nacionalizar a cultura brasileira.

Mário de Andrade considerava necessário realizar um projeto de grande envergadura no intuito de concentrar o saber de um povo em um "livro só". Essa visão tinha um propósito utilitário e nacionalista, e se alimentava do pensamento ilustrado e de sua ambição por reunir conhecimento de valor universal com o objetivo de popularizá-lo. Mário de Andrade estabeleceu que o peso da informação brasileira contida na Enciclopédia deveria representar 30\% da obra, pois entendia que era necessário integrá-la ao "universal". Entre os assuntos abordados pela Enciclopédia estariam: História Antiga e Moderna, Artes Plásticas, Filosofia, Direito, etc. Além disso, considerou-se importante que a obra fosse editada pelo poder público, sem preocupações comerciais, para poder alcançar todos os cantos do país. Desta maneira, a Enciclopédia não estaria destinada apenas a um grupo social, e sim a dois tipos básicos de leitores: por um lado, os trabalhadores e, por outro, os homens e as mulheres alfabetizadas que quisessem aprofundar seus conhecimentos (Amaral, 1997).

De seus estudos, o INL conseguiu publicar apenas algumas obras. Ainda que parecesse fundamental elaborar uma grande obra nacional, a dedicação de Mário de Andrade, Capanema e seus auxiliares não foi suficiente para enfrentar as dificuldades que envolviam um projeto que pretendia colocar o Brasil em uma única obra impressa. Talvez o projeto tenha sido planejado para um alcance excessivo e, por isso, a Enciclopédia e o Dicionário brasileiros jamais conseguiram fazer parte das pequenas bibliotecas particulares dos cidadãos.

\section{As BIBLIOTECAS PÚBLICAS: ENSINAR A LER O NACIONAL}

Os ideólogos estadonovistas não acreditavam que a ideia de democratização da cultura fosse contrária a um regime autoritário: a ditadura de Vargas foi considerada por muitos dos seus apoiadores - entre eles Oliveira Viana como uma democracia autoritária, cujo fundamento era o princípio de autoridade e não de liberdade (Abreu, 2008) (Arquivo Getúlio Vargas 14 nov. 19412). Nesse sentido, para o governo, a democratização da leitura deveria ser impulsionada pelo Estado por meio da criação de espaços de sociabilização do livro, como as bibliotecas. O Governo procurou influenciar a mudança de comportamento dos leitores para eles se multiplicarem, tanto quantitativamente quanto qualitativamente. A partir desta ideia, nasceram duas políticas adicionais: o INL controlaria a seleção de obras distribuídas nas bibliotecas públicas para que os livros oferecessem um conteúdo determinado; mas, por 
outro lado, iria se preocupar em satisfazer as preferências dos leitores, posto que essa era a única forma de "atrair" os potenciais leitores naquele contexto em que o livro concorria por espaço com o cinema e o rádio.

Sob a coordenação de Augusto Meyer, criou-se a Seção de Bibliotecas do INL, que tinha como objetivos principais auxiliar, registrar, manter e organizar as bibliotecas públicas em todo território nacional. Para isso, o poder público se inspirou nos modelos bem-sucedidos de outros países; e o modelo escolhido como referência para o Brasil foi o argentino. O sistema bibliotecário argentino consistia na provisão de livros por meio da Comisión Protectora de Bibliotecas Populares. Essa organização tinha como finalidade estabelecer uma rede de bibliotecas que, em 1937, alcançou a cifra de 1.483. Dos nove mil livros adquiridos em 1935 pela comissão argentina, 40\% eram de literatura (Arquivo Gustavo Capanema 7 set. 1934-1). Inspirados por esse projeto, Augusto Meyer e os ideólogos do projeto bibliotecário do Instituto também tentaram incentivar a aquisição de livros de literatura para nutrir os acervos das bibliotecas populares.

O sistema de bibliotecas públicas, criadas a partir da política de Estado, não somente tinha como propósito facilitar o acesso à leitura, mas também o interesse de direcionar as leituras. A doação de acervos para as diferentes bibliotecas foi organizada da seguinte maneira: as bibliotecas públicas e escolares receberiam doações regulares de obras adquiridas no mercado de publicações oficiais; as bibliotecas privadas, por sua vez, receberiam doações de publicações do Ministério da Educação. As medidas aplicadas se centraram no uso das bibliotecas para a divulgação da cultura oficial, dentro do projeto de doutrinação e nacionalização do povo e das elites, e o livro deveria ser o veículo de preservação e divulgação da história e dos valores culturais do país.

Em 24 de junho de 1941 foi criada a Biblioteca Getúlio Vargas na cidade de Pitangui (Minas Gerais) - cidade onde havia nascido o ministro de Educação, Gustavo Capanema -, destinada à divulgação da literatura nacional e popular. Contudo, como seu nome mesmo parece indicar, também serviu como propaganda do regime. No seu acervo, foram incluídas obras como Getúlio Vargas, de André Carrazzoni; A ação do Presidente Getúlio Vargas, de Eloy Pontes; As melhores páginas de Getúlio Vargas, de José Pereira da Silva; Getúlio Vargas, reformador social, de J. Paulo de Medeiros; O sorriso do presidente, de Paulo Roberto; e Estado Novo e suas diretrizes, de Monte Arrais (Arquivo Gustavo Capanema g 30 out. 1936). Também foram integradas ao acervo dessa biblioteca as obras do próprio Vargas.

Outra atribuição do Instituto correspondia à compra de livros de edito- 
ras privadas para, posteriormente, distribui-los gratuitamente em bibliotecas públicas registradas. Portanto, o INL foi cliente de algumas editoras que vendiam livros de autores apoiadores do regime e utilizou suas compras para promover a indústria editorial como forma de subsídio (Oiticica, 1997, p. 7). Por exemplo, as editoras Zélio Valverde, Civilização Brasileira e Editora José Olympio vendiam seus livros com preços reduzidos diretamente para as bibliotecas registradas pelo INL. O Instituto também se encarregava da publicação dos livros de caráter pouco comercial e que, por esta razão, as editoras não tinham interesse em publicar, mas que eram considerados pelo governo de grande valor cultural.

Numa sociedade em que a cultura letrada tinha um alcance limitado, o Instituto viu ser necessário empreender um amplo e difícil projeto de criação de uma rede de bibliotecas. Esta rede deveria possuir algumas bibliotecas centrais; núcleos que, por sua vez, deviam apoiar e organizar outros menores, ficando encarregados do controle da gestão das bibliotecas populares (espalhadas pelo território). Esse plano previa a criação de bibliotecas centrais em Belém, Bahia, Recife, Belo Horizonte, Rio de Janeiro, São Paulo e Porto Alegre. Cabia às mesmas orientar, distribuir e emprestar livros às bibliotecas de sua região. A cidade de Porto Alegre, por exemplo, coordenaria esse trabalho na Região Sul (isto é, nos estados de Santa Catarina, do Paraná e do Rio Grande do Sul). Do mesmo modo, para aumentar a circulação dos livros, foram criadas as bibliotecas ambulantes que percorreriam o interior do país, difundindo o livro nos lugares de difícil acesso. O INL, portanto, era o órgão coordenador das bibliotecas centrais; responsável pelas trocas entre elas e as bibliotecas municipais, bem como pela manutenção do catálogo coletivo dos acervos existentes no país, o qual reunia informações sobre todas as obras que faziam parte do acervo bibliotecário.

O trabalho do Instituto não foi fácil, mas a sua campanha de registro de bibliotecas e acervos teve resultados muito bons. Em 1941, foram registradas 1.325 bibliotecas e, cinco anos mais tarde, o número chegou a 3.680. Em 1942, o Ministério da Educação publicou dados sobre o registro das bibliotecas. No relatório constava que, no momento, já existiam "1.699 bibliotecas, concentradas, sobretudo, nas capitais", sendo que mais da metade delas, na época, eram públicas. O registro das bibliotecas originou o Guia das Bibliotecas Brasileiras, editado a partir de 1940 (Arquivo Gustavo Capanema 7 set. 1934-1). 


\begin{tabular}{|c|c|c|}
\hline \multicolumn{3}{|c|}{ Tabela 2 } \\
\hline BIBLIOTECAS REGISTRADAS ATÉ 31/12/1942 \\
\hline 1.699 Bibliotecas & Número & $\%$ \\
\hline Públicas e semipúblicas & 919 & $54 \%$ \\
\hline Privadas & 780 & $46 \%$ \\
\hline Volumes distribuídos até 31/12/1942 & \multicolumn{2}{|c|}{172.743} \\
\hline
\end{tabular}

Fonte: Elaboração própria a partir de dados recolhidos no Arquivo Gustavo Capanema 7 set. 1934-1.

Consideramos, portanto, que a maior conquista do Instituto foi o levantamento realizado pelo censo e a instalação de bibliotecas públicas e gratuitas. $\mathrm{O}$ acesso às bibliotecas tornou-se um direito naquele contexto de democratização da leitura. Outros dados também interessantes são os seguintes: do total de bibliotecas instaladas e registradas no Brasil, $48 \%$ eram escolares; houve um crescimento de bibliotecas públicas, sobretudo durante o período entre 1940 e 1941; de todas as bibliotecas, menos de $1 \%$ das registradas correspondiam a bibliotecas sindicais (Silva, 1992, p. 95).

\section{AS PUBLICAÇÕES DO ESPÍRITO NACIONAL}

A Seção de Publicações foi, provavelmente, a de maior sucesso das três seções criadas para implementar a política oficial estadonovista de promoção do livro. Sob a direção de Sérgio Buarque de Holanda, essa seção concentrou seus esforços na edição de obras raras e de grande interesse nacional para a formação cultural dos brasileiros. Eram consideradas obras raras aquelas que faziam parte do patrimônio intelectual brasileiro, mas que eram de difícil acesso para o público letrado. Ao Instituto competia realizar a impressão ou a reimpressão dessas obras. Do mesmo modo, o INL foi responsável pelo desenvolvimento das políticas públicas necessárias para melhorar, incrementar, difundir e baratear as edições de livros estrangeiros e, particularmente, de livros nacionais, assim como por intensificar a exportação de obras de autores brasileiros.

Cabia ao Instituto, ainda, divulgar coleções especiais e a bibliografia nacional, bem como organizar um sistema de fichas impressas para a distribuição das obras publicadas no Brasil, que seriam fornecidas gratuitamente às bibliotecas 
registradas no INL. Outra importante política implementada foi a recuperação de obras esgotadas. O Instituto se encarregaria da reedição de todas as obras artísticas, literárias e científicas de "real valor" que se encontravam esgotadas há mais de cinco anos, desde que seus autores, herdeiros ou proprietários não quisessem tomar essa iniciativa. O INL considerava que forneceria, assim, para o mercado de livros, obras de "valor positivo" e de grande interesse cultural para a formação nacional (Arquivo Gustavo Capanema 7 set. 1934-1. Seção...).

O INL, procurando criar uma tradição literária brasileira, também implementou a organização de bibliografias retrospectivas. Por meio da cooperação entre o Instituto e os escritores, as bibliografias individuais de grandes autores brasileiros, cuja publicação foi centralizada e orientada pela Seção de Publicações, estavam destinadas a servir de guia para futuras edições críticas. A publicação de trabalhos bibliográficos não elaborados diretamente pelo INL foi realizada mediante a aquisição dos direitos de autor ou por meio de subsídios a seus autores.

A opção pelo formato econômico orientou a política editorial do Instituto (Arquivo Gustavo Capanema 7 set. 1934-1. Seção...). Este encomendava às editoras e aos livreiros a edição e a venda de obras de interesse para o Estado a preços mais baixos - em especial à Editora José Olympio, principal beneficiária dessa relação. Portanto, é possível considerar que, apesar do trabalho do INL na busca de soluções para os problemas relativos ao livro, a instituição preferiu atuar por meio de publicações de formato simples e a preços reduzidos, a partir de uma política que beneficiou as editoras privadas.

As coleções populares editadas pela Seção de Publicações abrangeram, especialmente, obras originais e traduções, cujos direitos de autor já haviam passado ao domínio público, além de livros cujos direitos foram comprados pelo INL. Além disso, os ilustrados do Instituto optaram por escolher obras expressivas da literatura nacional, motivo pelo qual foi criada a Coleção Biblioteca Popular Brasileira. Como explica a historiadora Mariana Rodrigues Tavares, o objetivo principal dessa coleção era levar à população obras de qualidade e a preço acessível (Tavares, 2016, pp. 40-41). O critério de seleção foi baseado na raridade da obra e, portanto, privilegiou as obras clássicas de literatura, história, geografia e sociologia brasileiras.

A política institucional do INL se concentrou, prioritariamente, em reunir intelectuais reconhecidos para realizarem a seleção de obras consideradas fundamentais para a cultura letrada brasileira. Como bem indica a historiadora Lúcia Lippi Oliveira (1982), a historiografia costuma destacar o papel da intelligentsia nos aspectos de crítica e oposição à ordem estabelecida. No caso 
estudado aqui, no entanto, esses intelectuais participaram da construção do nacional, definindo uma tradição cultural para legitimar o projeto do regime. Assim, "como especialistas da dimensão simbólica da vida, [os intelectuais] desempenharam um papel vital na formulação do passado": seu esforço em recuperar o passado e criar uma tradição foi colocado a serviço da legitimação da autoridade política (Oliveira, 1982, pp. 33-34).

Ao mesmo tempo, entretanto, os intelectuais também deixaram sua marca nas políticas oficiais. Para Pécaut (1990), o Estado procurou cooptá-los, apropriando-se das representações propostas pelos intelectuais; estes, por sua vez, muitas vezes estavam dispostos a se inspirarem nas representações professadas pelo Estado. Esse processo dialógico contribuiu decisivamente para a imposição de novas representações do político, nas quais os intelectuais tinham uma responsabilidade principal: a construção de uma representação da nação por meio, sobretudo, da literatura. Desta forma, como aponta Randal Johnson (1995, p. 171), a literatura e a política tornaram-se inseparáveis.

O Instituto deveria promover e estimular que o grande público conhecesse obras clássicas da literatura, particularmente da literatura brasileira, e obras de especial interesse nacional. Para tal fim, o Instituto deveria editar livros em formato simples e a preços módicos. Nesse contexto, receberam especial atenção do Instituto a publicação e o fomento de livros de ficção, particularmente os romances, como podemos verificar, por exemplo, na listagem de livros remetidos pelo INL à Biblioteca Getúlio Vargas (Pitangui):

Gráfico 1: Livros remetidos pelo INL à Biblioteca Getúlio Vargas

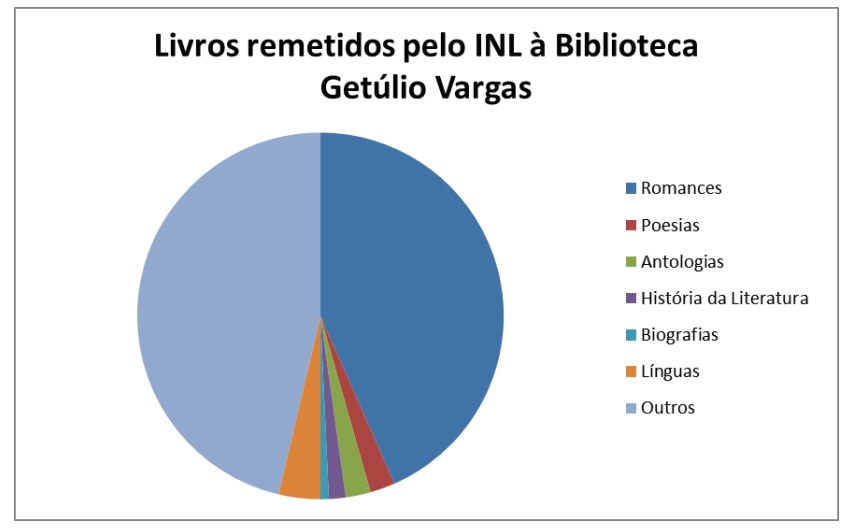

Fonte: Elaboração própria a partir dos dados recolhidos no Arquivo Gustavo Capanema 30 out. 1936 (CPDOC/FGV). 
Os títulos publicados pelo INL indicam uma linha editorial direcionada especialmente ao gênero romance, assim como aos clássicos da literatura brasileira. O regime, pois, concebeu a literatura como elemento central na construção da nação. Por isso, em 1943, o Instituto organizou, junto com um grupo de escritores encabeçados por Múcio Leão, a publicação da obra História da Literatura Brasileira (Arquivo Gustavo Capanema 7 set. 1934-1. Seção...).

Esse trabalho foi dividido em vários volumes, nos quais deviam figurar todos os aspectos da produção intelectual do país. Entre os integrantes da comissão e seus colaboradores, podemos citar nomes tais como os de Cassiano Ricardo, Afrânio Peixoto, Carlos Drummond de Andrade, Gilberto Freyre, Manuel Bandeira, Mário de Andrade, Oliveira Viana, Prudente de Morais Neto, Sérgio Buarque de Holanda, Viana Moog e Alceu Amoroso Lima.

Essas coleções, particularmente a Biblioteca Popular Brasileira, deveriam ser publicadas pelo Instituto e comercializadas a preços muito baixos. Para implementar esse projeto de construção das pequenas bibliotecas particulares dos brasileiros com as obras mais expressivas da produção cultural do país, o Instituto começou com a literatura brasileira do período colonial, da qual seria extraído o material básico para a Antologia da Poesia Brasileira da Fase Colonial. Muitas dessas obras eram autênticas raridades bibliográficas e foram recuperadas pelo INL, como, por exemplo, a Vida do Venerável Padre José de Anchieta, de Simões de Vasconcelos, cuja edição original foi publicada em 1672, em Lisboa, e jamais fora reimpressa. Enquanto essa obra era vendida por livrarias e sebos pelo valor de cinco mil cruzeiros ou mais, o Instituto organizou uma nova reimpressão que custava apenas quatro cruzeiros.

De acordo com o plano traçado pela instituição, deviam ser publicados, mensalmente, um ou dois volumes da Biblioteca Popular Brasileira. O Estado Novo queria criar um corpus de livros canônicos da literatura nacional e escolheu o formato de antologia. Previa-se, para o ano de 1945, a publicação dos primeiros cinquenta volumes da coleção. Entre as primeiras publicações, estavam as seguintes: as Poesias Completas do poeta simbolista e filho de escravizados libertos Cruz e Souza (1861-1898); a obra do romancista Manuel Antônio de Almeida Memórias de um sargento de milícias, que retrata as classes média e baixa urbanas por meio de um personagem "pícaro", um anti-herói; e a obra de Teixeira e Souza $O$ filho do pescador, considerado o primeiro romance brasileiro do século XIX. Foram publicadas, também, antologias do Arcadismo, do Romantismo, do Parnasianismo, do Simbolismo e do Neo-parnasianismo (Arquivo Gustavo Capanema 24, Pasta III - 712).

Em 1939, a Seção de Publicações organizou a edição dos seguintes livros: 
a obra completa de José Bonifácio (dividida em quatro partes: obra literária, científica, política, correspondência e apontamentos avulsos); a Antologia Romântica e antologia Parnasiana (com comentários de Manuel Bandeira); o catálogo da exposição de Machado de Assis, na qual foram expostos seus livros mais representativos e em formato não econômico, assim como uma bibliografia especializada sobre ele; a bibliografia especializada de Tobias Barreto; a de Tavares Bastos; a de Casimiro de Abreu; a de Floriano Peixoto; Espumas Flutuantes, de Castro Alves; a bibliografia documentada da História do Rio Grande do Sul; e a Bibliografia Goethiana sobre o Brasil'.

Ainda que alguns acadêmicos, estudiosos do INL (Suely, 1992), afirmem que este não fez parte dos veículos de difusão das ideias estadonovistas, observa-se que o Instituto figurou como um dos órgãos que gerou um sistema de universalização de valores pertencentes à classe dominante e foi um eficiente instrumento do poder estatal (Tavares, 2014). Tanto as antologias quanto as denominadas bibliografias especializadas (não apenas de escritores, mas também de políticos, como Floriano Peixoto) foram publicações que pretendiam reunir e representar os "homens mais ilustres" da nação. Essas obras também serviam como referência da "boa leitura" nacional: elas formariam o espírito dos brasileiros e os modelos morais a seguir. Selecionar o passado para construir o futuro: desta maneira poderia ser construída uma "tradição" com o objetivo de se descobrir o tempo pretérito, mas adequando-o ao status quo. Nessa seleção, eram excluídos alguns textos e outros eram incluídos: o presente era "o ponto de inserção em que a história é constituída pela seleção da presença do passado no futuro" (Gomes, 1982, p. 11). É claro, no entanto, que não faltaram critérios ambíguos para a inclusão de determinados autores no panteão nacional. Um bom exemplo dessa ambiguidade é o escritor Joaquim Maria Machado de Assis.

Considerado o melhor escritor brasileiro, Machado de Assis (1839-1908) foi um intelectual de intensa atividade, sobretudo como jornalista, romancista e contista. Diferentemente da narrativa romântica indianista de José de Alencar, que logo será analisada, Machado de Assis utiliza um tom "moderno" na sua escrita, ambientando as suas obras num cenário urbano que incluía tanto os círculos aristocráticos quanto os dos pobres de subúrbio. Entre as coleções organizadas pelo Instituto, encontramos suas produções mais importantes: Helena, Iaiá Garcia, Memórias Póstumas de Brás Cubas, Dom Casmurro, Poesias Completas, Correspondências, Quincas Borba, Esaú e Jacó, Histórias sem data, Papéis Avulsos, A Semana e Memorial de Aires (Arquivo Gustavo Capanema g 30 out. 1936). 
Diferentemente da literatura considerada de grande valor nacional por promover a brasilidade, Machado de Assis não elaborou suas narrativas procurando valorizar as "raízes brasileiras", nem se empenhou na formação da identidade nacional. A brasilidade, para ele, devia ser interior, heterogênea e não um mero verniz superficial (Schwarz, 2008, p. 8). Talvez ele possa ser considerado a "grande exceção" na literatura fomentada a partir das esferas oficiais. Por esse motivo, como destaca a historiadora Mônica Velloso (1988), a crítica literária do Estado Novo empenhou-se em desqualificar sua obra por não ser suficientemente "nacionalista".

Apesar disso, e ainda que Velloso argumente que a obra machadiana entra em conflito com o projeto literário estadonovista, as obras de Machado de Assis foram amplamente fomentadas pelo Instituto, sendo produzidas coleções e exposições sobre sua vida e sua obra. Por isso, entendemos que o INL não pensava que sua produção literária destoasse totalmente do projeto do regime. Nos primeiros romances de Machado de Assis, como Helena e Iaiá Garcia, é evidente a sua posição antiliberal e seu conservadorismo (Schwarz, 2008). Posteriormente, na sua etapa mais "madura", suas críticas se valeram, fundamentalmente, da paródia às doutrinas sociais e científicas, da crítica à hipocrisia da sociedade burguesa e capitalista e das oligarquias locais (como em Quincas Borba, Dom Casmurro e Memórias Póstumas de Brás Cubas).

Como funcionário do Império, Machado de Assis, assim como Getúlio Vargas, sempre admirou D. Pedro II, por este ser amante das letras e por ter possibilitado a unidade nacional sob um governo centralizador. Como assinalou Hélio de Seixas Guimarães (2007, p. 261), “daí que Machado de Assis fosse favorável ao centralismo do Império e simpatizasse com o sistema parlamentar; porém, desacreditava da República porque previa que ela se assentaria em um federalismo oligárquico". É possível inferir que o regime varguista se apropriou da literatura de Machado de Assis, colocando-a a serviço do projeto de nacionalismo do Estado Novo, a partir de uma "leitura que se ajustava ao ideário trabalhista do governo", ao retratar o autor como modelo exemplar de alguém que superou as adversidades (pobreza, racismo etc.) através do estudo e do trabalho (Guimarães, 2011) ${ }^{10}$. Assim, ainda que os escritos machadianos fossem de um nacionalismo bem mais pessimista e oferecessem uma visão pouco idílica da sociedade brasileira, de acordo com Thiago Salla (2012), o governo empenhou-se em colocar em destaque suas obras, embora muitos intelectuais estadonovistas ${ }^{11}$ também o criticassem, dada a falta de "cor local" dos seus escritos.

Nesse sentido, em 20 de junho de 1939, na comemoração do centenário 
de nascimento do escritor, por meio do Decreto-lei n. 1360, foram realizadas, a cargo do INL, exposições e edições críticas e ilustradas de suas obras, e foi instituído o Prêmio Machado de Assis (Arquivo Gustavo Capanema 7 set. 1934-1). Outrossim, o processo de consagração do escritor como uma "glória nacional" ocorreu por meio do aparato propagandístico de Vargas, que explorou em Machado de Assis sua imagem de homem trabalhador, "mulato", autodidata e moderno. Seria possível concluir que, durante o Estado Novo, Machado de Assis foi transformado em "patrimônio cultural brasileiro" (Ferreira, 2011, p. 45).

A partir dessa lógica, as editoras também se interessaram em publicar os livros de Machado de Assis. Foi o caso da Sociedade dos Cem Bibliófilos do Brasil, que publicou, em 1943, Memórias Póstumas de Brás Cubas, com ilustrações de Cândido Portinari. Um ano depois, a editora brasileira Atlântica Editora publicou, em francês, a mesma obra, com tradução do General Chadebec de Lavalade, antigo chefe da Missão Militar Francesa no Brasil. Essa versão foi apresentada ao público por Afrânio Peixoto, na Academia Brasileira de Letras. Esta obra também seria o primeiro volume da coleção Les maîtres des littératures américaines, seguida pela tradução do romance Memórias de um sargento de milícias, do escritor carioca Manuel Antônio de Almeida, e, posteriormente, pelas obras São Bernardo, Vidas Secas e Angústia, de Graciliano Ramos. Outros autores como José Lins do Rego, Jorge Amado, Raquel de Queiroz, Aluísio de Azevedo, Raul Pompéia e Lima Barreto também tiveram suas obras publicadas por essa editora. É interessante observar, entretanto, que as obras de alguns escritores "exportados" não foram divulgadas internamente: é o caso, por exemplo, do escritor Lima Barreto (1881-1922). Todos esses livros foram distribuídos em países latino-americanos, nos Estados Unidos, no Canadá, na Inglaterra, na África do Norte e na França (Arquivo Gustavo Capanema 7 set. $1934-1)^{12}$.

No entanto, o governo não difundiu somente as obras machadianas; as obras do romantismo brasileiro também foram amplamente difundidas pelo Instituto Nacional do Livro. A partir da Independência do Brasil, em 1822, aumentou o sentimento nacionalista no país e passou a ser necessário imaginar uma nação e forjar uma identidade. Nesse contexto, no ano de 1836, surgiu, no Brasil, uma nova escola literária. Foi quando o poeta Gonçalves de Magalhães publicou suas poesias românticas Suspiros poéticos e saudades (obra posteriormente reeditada com o apoio do INL). O romance histórico e a poesia nacionalista foram o principal meio de os escritores alcançarem o compromisso com a identidade nacional. Os escritores românticos começaram a observar 
o passado brasileiro e encontraram, como personagem principal, a população que habitava o território antes do violento processo de colonização: os indígenas.

Essa visão nacionalista, centrada na construção de uma identidade brasileira, estava plenamente em sintonia com a proposta identitária defendida pelo regime. Por tudo isso, o Instituto, com o apoio de um grande grupo de escritores, começou a organizar coleções de livros, cursos e exposições sobre o romantismo. Intelectuais de diversas orientações políticas participaram de conferências para tratar de aspectos particulares do romantismo brasileiro. Entre os participantes, estavam os seguintes intelectuais: Gustavo Barroso, Afrânio Peixoto, Alceu Amoroso Lima, Mário de Andrade, Manuel Bandeira, Gilberto Freyre, Sérgio Buarque de Holanda, Prudente Moraes Netto e Múcio Leão. Os temas tratados foram: o nacionalismo, o indianismo e o sertanismo. O Instituto também organizou as chamadas Edições críticas, que tratavam de obras de alguns poetas e romancistas: uma espécie de antologia com estudos críticos e comentários realizados por intelectuais especialistas das obras em questão.

Contudo, o INL dispensou um tratamento especialmente destacado a José de Alencar (1829-1877), organizando a edição de suas Obras completas. A família do escritor concedera os direitos autorais dos trabalhos inéditos de Alencar para que, assim, eles fossem incorporados nas suas obras completas. O escritor Mário de Alencar, com o auxílio do chefe da Seção de Publicações, Sérgio Buarque de Holanda, traçou o plano das publicações, que contaria com vinte e nove grandes volumes, da mesma forma que foi ele, também, o autor do prefácio dos tomos correspondentes. O primeiro volume foi dedicado ao romance $O$ Guarani. Nessa obra, foi incluída uma introdução de Mário de Alencar, uma biografia e uma bibliografia cronológica de José de Alencar, assim como um prefácio de Machado de Assis. O plano editorial contemplava a publicação anual de, pelo menos, cinco volumes, para que, depois de cinco ou seis anos, fossem publicadas as obras completas do romancista (Arquivo Gustavo Capanema 7 set. 1934-1).

Os ideólogos e intelectuais do Estado Novo, como bem aponta Seth Garfield (2000), subverteram a concepção eurocêntrica da história cultural-literária, quando encontraram nos indígenas (e também nos afrodescendentes, a partir dos modernistas) os personagens essenciais, não apenas da nacionalidade brasileira como do próprio destino da Nação. Essa representação foi utilizada tanto no século XIX como no século XX, pois todos os modernistas tinham uma concepção nacionalista similar de revalorização de uma identidade étnico-cultural mestiça e de glorificação do passado. A compreensão dos povos 
originários como primeiros cidadãos brasileiros se tornou a imagem escolhida pelo regime de Vargas. O indígena, em seu desenvolvimento cívico, deveria trabalhar para tornar o interior do país produtivo. Em contrapartida, o Estado prestaria assistência através da saúde pública, da educação e do transporte. No que diz respeito à integração nacional, a obra de Cassiano Ricardo Marcha para o Oeste foi transformada em símbolo do Estado Novo: isto é, o Brasil precisava interiorizar-se, e os povos nativos teriam um papel central nessa marcha para o oeste.

\section{CONSIDERAÇÕES FINAIS}

Como foi exposto ao longo deste artigo, cultura e política estiveram vinculadas, estabelecendo, durante o Estado Novo de Vargas, uma dimensão completamente nova: os intelectuais consideravam a si mesmos como um grupo ideal para transmitir a consciência nacional, reivindicando, com isso, o papel de condutores e defensores da cultura (Velloso, 1987). No entanto, cabe salientar que estes intelectuais não foram uma simples ferramenta utilizada pelo Estado. Muito pelo contrário: eles imprimiram, nas políticas culturais oficiais, os seus próprios projetos modernistas, muitas vezes na contramão do próprio projeto ideológico varguista (Grecco, 2021).

Através da literatura, o passado operou como uma "fonte de inspiração" (Gomes, 1982, p. 144). Mas não se tratava, apenas, de olhar para trás e reproduzir aquilo que tinha sido realizado: era feita uma releitura positiva do passado através dos literatos e da construção de uma cultura realmente brasileira. Assim, como se fosse um mito palingenésico, a Nação renascia sob o comando de Vargas depois do período de decadência ocorrido no passado mais imediato (isto é, durante o liberalismo da República Velha). O governo, junto com a intelligentsia, buscou a integração de modelos do passado com a renovação do presente. O Estado exigiu pensar o país historicamente, e isso permitiria que ele chegasse a uma cultura histórica de consenso. Dessa forma, a construção da memória implicava travarem-se diversas batalhas simbólicas por meio da apropriação de eventos: alguns fatos deviam ser lembrados, outros esquecidos. Efetivamente, cada etapa histórica constrói sua memória e, também, seus heróis, os quais oferecem modelos para a construção de uma identidade coletiva (Bomeny, 2001, p. 44).

Neste contexto de dessacralização da leitura, em um processo de ampliação do público leitor e de formação dos brasileiros, o Instituto Nacional do Livro, em sintonia com os avanços do mercado editorial e com os vínculos com as 
editoras privadas, esteve imbuído de uma missão político-social a qual buscava garantir o acesso à leitura e criar um sentimento de pertencimento à ideia de Brasil construída pelo governo estadonovista. O Estado Novo, com a ajuda do INL e de uma elite intelectual, construiu novas formas de poder na regulação e na difusão da palavra impressa. E, nesta lógica, a relação entre Governo e intelectuais-escritores foi forjada numa situação de equilíbrio instável: muitos deles não serviram ao Estado, senão se serviram do Estado, imprimindo suas marcas nas políticas culturais oficiais (Velloso, 1987, p. 4; Grecco, 2021, p. 176).

\section{REFERENNCIAS}

ARQUIVO GETÚLIO VARGAS c 24 dez. 1937, Rio de Janeiro (Centro de Pesquisa e Documentação de História Contemporânea do Brasil - Fundação Getúlio Vargas).

ARQUIVO GETÚLIO VARGAS 14 nov. 1941-2, Rio de Janeiro (Centro de Pesquisa e Documentação de História Contemporânea do Brasil - Fundação Getúlio Vargas).

ARQUIVO GUSTAVO CAPANEMA 24, Pasta III - 712, Rio de Janeiro (Centro de Pesquisa e Documentação de História Contemporânea do Brasil - Fundação Getúlio Vargas).

ARQUIVO GUSTAVO CAPANEMA g 30 out. 1936, Rio de Janeiro (Centro de Pesquisa e Documentação de História Contemporânea do Brasil - Fundação Getúlio Vargas).

ARQUIVO GUSTAVO CAPANEMA 7 set. 1934-1, Rio de Janeiro (Centro de Pesquisa

e Documentação de História Contemporânea do Brasil - Fundação Getúlio Vargas).

ARQUIVO GUSTAVO CAPANEMA 7 set. 1934-1. Seção de Publicações 1939, Rio de Janeiro (Centro de Pesquisa e Documentação de História Contemporânea do Brasil - Fundação Getúlio Vargas).

ABREU, Luciano Aronne de. Autoritarismo e Democratismo: uma leitura do Estado Novo. In: IX ENCONTRO ESTADUAL DE HISTÓRIA - VESTÍGIOS DO PASSADO, n. 9, 2008, Porto Alegre. Anais Eletrônicos - IX Encontro Estadual de História - ANPUH. Porto Alegre: IFCH-UFRGS, 2008. pp. 1-10.

AMARAL, Adriana Facina Gurgel do. Uma enciclopédia à brasileira: o projeto ilustrado de Mário de Andrade. Estudos Históricos, v. 13, n. 24, pp. 394-417, 1999.

ANASTASIA, Carla. Artífices e difusores de uma nova Nação material: a coleção Brasiliana e as bases da institucionalização burocrática no pós-30, 2003. Mimeografado. 
BOMENY, Helena (Org.). Constelação Capanema: intelectuais e políticas. Rio de Janeiro: Ed. Fundação Getúlio Vargas; Bragança Paulista (SP): Ed Universidade de São Francisco, 2001.

BRAGANÇA, Aníbal. As políticas públicas para o livro e a leitura no Brasil: o Instituto Nacional do Livro (1937-1967). Matrizes, São Paulo: USP, v. 2, n. 2, pp. 221-246, 2009.

CHARTIER, Roger (Org.). Práticas de leitura. São Paulo: Estação Liberdade, 1996.

CHARTIER, Robert. Pluma de ganso, libro de letras, ojo viajero. México DF: Universidad Iberoamericana, 2005.

CONFERÊNCIA A ESPIRITUALIDADE DA LÍNGUA: Arquivo Gustavo Capanema 7 set. 1934-1 (Centro de Pesquisa e Documentação de História Contemporânea do Brasil - Fundação Getúlio Vargas).

COSTA, Renata. Caminhos paralelos da produção de jornais e livros no Brasil. INTERCOM - CONGRESSO BRASILEIRO DE CIÊNCIAS DA COMUNICAÇÃO, XXXII, 2009, Curitiba. XXXII Congresso Brasileiro de Ciências da Comunicação [Anais]. Curitiba, 2009. pp. 1-15.

DUTRA, Eliana de Freitas. Companhia Editora Nacional: Tradição Editorial e Cultura Nacional no Brasil nos anos 30. SEMINÁRIO BRASILEIRO SOBRE LIVRO E HISTÓRIA EDITORIAL, I, 2004, Casa de Rui Barbosa. Seminário brasileiro sobre livro e história editorial. Rio de Janeiro: FCRB - UFF/PPGCOM - UFF/LIHED, 2004. pp. 1-22.

DUTRA, Eliana de Freitas; MOLLIER Jean-Yves (Orgs.). Política, nação e edição: o lugar dos impressos na construção da vida política. São Paulo: Annablume Editora, 2007.

ESTADÍSTICAS HISTÓRICAS DO BRASIL. Séries Econômicas, Demográficas e Sociais 1550 a 1988, 2. Ed, Rio de Janeiro: IBGE, 1990.

FERREIRA, Gabriela Manduca. A crítica machadiana durante o Estado Novo. Dissertação (Mestrado em Literatura Brasileira) - Faculdade de Filosofia, Letras e Ciências Humanas, Universidade de São Paulo. São Paulo, 2011.

FRANZINI, Fábio. À Sombra das Palmeiras. A Coleção Documentos Brasileiros e as transformações da historiografia nacional (1936-1959). Tese (Doutorado em História) - Departamento de História da Faculdade de Filosofia, Letras e Ciências Humanas, Universidade de São Paulo. São Paulo, 2006.

GARFIELD, Seth. As raízes de uma planta que hoje é o Brasil: os índios e o Estado-Nação na era Vargas. Revista Brasileira de História, São Paulo, v. 20, n. 39, pp. 13-36, 2000.

GLEDSON, John. Machado de Assis e a crise dos quarenta anos. Machado de Assis em linha, v. 4, n. 8, pp. 10-31, 2011.

GOMES, Ângela Maria de Castro. O redescobrimento do Brasil. In: OLIVEIRA, Lúcia Lippi; VELLOSO, Mônica Pimenta; GOMES, Ângela Maria de Castro (Orgs.). Estado Novo: ideologia e poder. Rio Janeiro: Zahar Ed., 1982. pp. 109-150. 
GRECCO, Gabriela de Lima. Literary Censorship in Francisco Franco's Spain and Getulio Vargas' Brazil, 1936-1945: Burning Books, Awarding Writers. Sussex Academic Press: Brighton, 2020.

GRECCO, Gabriela de Lima. Palavras que resistem: Censura e promoção literária na ditadura de Getúlio Vargas (1937-1945). Rio de Janeiro: 7Letras, 2021.

GUIMARÃES, Hélio de Seixas. O Machado terra-a-terra de John Gledson. Novos estud. - CEBRAP, São Paulo, n. 77, pp. 261-271, 2007.

GUIMARÃES, Hélio de Seixas. "Um apólogo - Machado de Assis”: do escritor singular ao brasileiro exemplar. Machado de Assis em linha, Rio de Janeiro, v. 4, n. 8, pp. 90-101, 2011.

HALLEWELL, Laurence. O livro no Brasil: sua História. São Paulo: Edusp, 2012.

JOHNSON, Randal. A dinâmica do campo literário brasileiro (1930-1945). Revista USP, São Paulo, n. 26, pp. 164-181, 1995.

LEITÃO, Bárbara Júlia Menezello. Bibliotecas públicas, bibliotecários e censura na Era Vargas e Regime Militar. Rio de Janeiro: Editora Interciência, 2011.

MICELI, Sergio. Intelectuais e classe dirigente no Brasil (1920-1945). São Paulo: Difel, 1979.

MICELI, Sergio. Intelectuais à brasileira. São Paulo: Companhia das Letras, 2001.

MUSIEDLAK, Didier. Intelectuais e Estado. O Exemplo da Itália fascista. In: RIDENTI, Marcelo; BASTOS, Elide Rugai; ROLLAND, Denis (Orgs.). Intelectuais e Estado. Belo Horizonte: UFMG, 2006. pp 81-94.

OITICICA, Ricardo Beserra da Rosa. O Instituto Nacional do Livro e as ditaduras: Academia Brasílica dos Rejeitados. Tese (Doutorado em Letras), Pontifícia Universidade Católica do Rio de Janeiro. Rio de Janeiro, 1997.

OLIVEIRA, Lúcia Lippi. O pensamento de Almir de Andrade. In: OLIVEIRA, Lúcia Lippi; VELLOSO, Mônica Pimenta; GOMES, Ângela Maria de Castro (Orgs.). Estado Novo: ideologia e poder. Rio Janeiro: Zahar Ed., 1982. pp. 31-47.

OLIVEIRA, Zita Catarina Prates de. A biblioteca "fora do tempo": políticas governamentais de bibliotecas públicas no Brasil, 1937-1989. Tese (Doutorado em Ciências da Comunicação) - Escola de Comunicações e Artes, Universidade de São Paulo. São Paulo, 1994. $221 \mathrm{f}$.

PAGANO, Adriana. An Item Called Books: Translations and Publishers' Collections in the Editorial Booms in Argentina and Brazil from 1930 to 1950. Crop, São Paulo: FFLCH, n. 6, pp. 171-194, 2001.

PANDOLFI, Dulce (Org.). Repensando o Estado Novo. Rio de Janeiro: FGV, 1999.

PASSIANI, Enio. Na trilha do Jeca: Monteiro Lobato, o público leitor e a formação do campo literário no Brasil. Sociologias, Porto Alegre, ano 4, n. 7, pp. 254-270, 2002. PÉCAUT, Daniel. Os intelectuais e a política no Brasil: entre o povo e a nação. São Paulo: Ática, 1990. 
SALLA, Thiago Mio. O Estado Novo e as críticas a Machado de Assis na primeira metade dos anos 1940. Machado Assis em linha, Rio de Janeiro, v. 5, n. 10, pp. 83 101, 2012.

SCHWARZ, Roberto. Um mestre na periferia do capitalismo: Machado de Assis. São Paulo: Livraria Duas Cidades, 2008.

SERRANO, Gisella de Amorim. Historiografia brasileira a partir da coleção Reconquista do Brasil. In: SEMINÁRIO NACIONAL DE HISTÓRIA DA HISTORIOGRAFIA: TEMPO PRESENTE \& USOS DO PASSADO, 4, 2010, Ouro Preto. NICOLAZZI Fernando; MOLLO, Helena; ARAUJO, Valdei (Orgs.). Caderno de resumos \& Anais do $4^{\circ}$. Seminário Nacional de História da Historiografia: tempo presente \& usos do passado. Ouro Preto: UFOP, 2010. pp. 1-13.

SERRANO, Gisella de Amorim. Caravelas de Papel: A Política editorial do Acordo Cultural de 1941 e o pan-lusitanismo (1941-1949). Lisboa: Instituto Camões, 2014.

SILVA, Einstein Augusto da. Crônicas e identidade nacional: um esboço à Machado. Considerações sobre identidade nacional nas crônicas de Machado de Assis. Dissertação (Mestrado em História) - Faculdade de História, Universidade Federal de Goiás. Goiânia, 2012.

SILVA, Suely Braga da. O Instituto Nacional do Livro e a institucionalização de organismos culturais no Estado Novo (1937-1945): planos, ideias e realizações. Dissertação (Mestrado em Ciência da Informação do CNPq/IBICT em convênio com a UFRJ/ECO) - Escola de Comunicação da UFRJ, Universidade Federal do Rio de Janeiro. Rio de Janeiro, 1992. $155 \mathrm{f}$.

SORÁ, Gustavo. Brasilianas: José Olympio e a gênese do mercado editorial brasileiro. São Paulo: Edusp, 2010.

SOUZA, José Inácio de Melo. O Estado contra os meios de comunicação (1889-1945). São Paulo: Annablume; FAPESP, 2003.

TAVARES, Mariana Rodrigues. Editando a nação e escrevendo sua história: O Instituto Nacional do Livro e as disputas editoriais entre 1937-1991. Aedos, v. 6, n. 15, pp. 164-180, 2014.

TAVARES, Mariana Rodrigues. Um Brasil inapreensivel: história dos projetos da Enciclopédia Brasileira do Instituto Nacional do Livro. Dissertação (Mestrado em História) - Programa de Pós-graduação em História Social, Universidade Federal Fluminense. Niterói, 2016. $138 \mathrm{f}$.

TOLEDO, Maria Rita de Almeida. Coleção atualidades pedagógicas: do projeto político ao projeto editorial (1931-1981). Tese (Doutorado em Educação) - Programa de Estudos Pós-Graduados em Educação: História, Política, Sociedade, Pontifícia Universidade Católica de São Paulo. São Paulo, 2001. 338 f.

TURATI, Filippo. Le Biblioteche del popolo. Milano: Consorzio delle Biblioteche popolari, 1905.

VELLOSO, Mônica Pimenta. A literatura como espelho da nação. Estudos Históricos, Rio de Janeiro, v. 1, n. 2, pp. 239-263, 1988. 
VELlOSO, Mônica Pimenta. Os intelectuais e a política cultural do Estado Novo. Rio de Janeiro: Fundação Getúlio Vargas; CPDOC, 1987.

ZILBERMAN, Regina; LAJOLO, Marisa. A formação da leitura no Brasil. São Paulo: Ática, 1996.

\section{NOTAS}

${ }^{1}$ Este texto está financiado pela Comunidade de Madrid através do Acordo Plurianual com a Universidade Autónoma de Madrid na sua linha de ação de incentivo à investigação de jovens doutores, no âmbito do V PRICIT (V Plano Regional de Investigação Científica e Inovação Tecnológica) (Referencia SI1/PJI/2019-00257).

${ }^{2}$ Sobre este tema, ver Grecco, 2020.

${ }^{3}$ Definida por alguns autores como modernização conservadora. Cf., por exemplo, Miceli (1979) e Pandolfi (1999).

${ }^{4}$ Como destacou Renata Costa (2009), neste período a maioria dos escritores dedicava-se aos jornais, às revistas e aos almanaques. A autora também salienta que a publicação da obra Os Sertões (1902), narrativa jornalístico-literária, foi o início do caminho de uma literatura que mostrava a realidade social do país, mas também representava a ponte entre romance e jornalismo e, por conseguinte, a consagração da literatura entre o público leitor.

${ }^{5}$ Sobre este tema, ver Zilberman e Lajolo, 1996.

${ }^{6}$ Em relação ao público leitor, os livros passaram a ser editados para diferentes categorias de leitores, através, especialmente, das coleções especializadas (voltadas aos jovens, aos profissionais, às mulheres, às crianças, etc.). A este respeito, cf. Dutra; Mollier, 2007.

${ }^{7}$ Sobre este completo universo das práticas que confluem na evolução e na construção da cultura escrita, ver Chartier, 1996.

${ }^{8}$ Sobre este tema, ver, também, Serrano, 2010; Franzini, 2006; Anastasia, 2003.

${ }^{9}$ Livro sobre a influência do Brasil na obra do autor de Fausto, já que, em suas anotações, aparecem oitenta e quatro referências ao país.

${ }^{10}$ Ver, também, Silva, 2012.

${ }^{11}$ Especialmente os intelectuais ligados ao Departamento de Imprensa e Propaganda (DIP).

${ }^{12}$ Sobre este tema de exportação de obras e acordos de atividades culturais, ver a obra de Serrano, 2014.

Artigo submetido em 25 de janeiro de 2021.

Aprovado em 12 de julho de 2021. 